(RESEARCH ARTICLE)

\title{
Light intensity of the light-curing units in private clinics in the city of Cuenca, Ecuador
}

Fernando Mauricio Villalta Mendoza 1, ${ }^{*}$, Anabel Priscila Rodas Jaramillo ${ }^{1}$, Joe Javier Lalangui Matamoros ${ }^{2}$, Ana Mischell Ajila Bohórquez ${ }^{2}$ and Iván Andrés Palacios Astudillo ${ }^{3}$

\author{
${ }^{1}$ Bachelor in General Dentistry Faculty of Dentistry, University of Cuenca. \\ 2 Student of Faculty of Dentistry, University of Cuenca. \\ ${ }^{3}$ Associate Professor of Faculty of Dentistry, University of Cuenca.
}

Publication history: Received on 31 October 2020; revised on 09 November 2020; accepted on 11 November 2020

Article DOI: https://doi.org/10.30574/wjarr.2020.8.2.0415

\begin{abstract}
Introduction: Light intensity emitted by the curing lamps represents an essential factor in the activation of photosensitive materials. The adequate supply of intensity, as well as the correct functioning of the device, it ensures a correct dental treatment. Objective: To know the light intensity, type, and fiber state of the curing lamps used in private dental offices in the city of Cuenca - Ecuador. Materials and methods: The cross-sectional descriptive study assessed the light intensity of 366 light-curing lamps from private clinics with the use of a Bluephase Meter II radiometer, besides the Likert-scale based evaluation of its type and condition. Data analysis was done with the software R v.3.2 and its interface R-Studio v.1.2. Results: Inadequate light intensities were observed in $18 \%$ of the total analyzed units. Inadequate light intensities corresponded at $46 \%$ of Halogen lamps, and 12\% of LED units. Likewise, 17\% of units presented fiber fracture, while $52 \%$ showed residues of biomaterials on it. The predominant diameter in the units was $8 \mathrm{~mm}$, representing $65 \%$ of the total of light-curing lamps analyzed. Conclusions: LED lamps presented adequate light intensities in higher proportion in comparison to halogen lamps. It was shown that the presence of fractures and residues decrease the intensity of the photocuring units. Furthermore, we indicate that a periodic control of the lightcuring units is necessary to prevent future problems in oral treatments.
\end{abstract}

Keywords: Light intensity; Light Curing Lamps; Optical fiber; Dental radiometer

\section{Introduction}

Photocuration lamps are of higher importance in dentistry due to the use of photoactive material in several treatments such as: direct and indirect restorations, cementation of orthodontics accessories, and grooves sealing, among others $[1,2]$. Light curing units must present a minimum light intensity of $400 \mathrm{~mW}^{*} \mathrm{~cm}-2$ [3-8] to guarantee the success of the dental treatments. Light intensity is defined as the number of photons emitted by the device with its measuring units in milliwatts per square centimeters $\left(\mathrm{mW}^{*} \mathrm{~cm}-2\right)$ [9]. Clinic repercussions of deficient light intensities comprehend marginal micro-filtrations, solubility affectation, dimensional stability, and restoration discoloration with further development of dental caries $[10,11]$.

Light sources are available in four types: Halogen, Light Emission Diode (LED), Xenon Plasma Arc (PAC) and Laser [12]. Halogen and LED are the most used in private dental clinics [13, 14]. Halogen lamps were introduced in the '70s [15] and were considered as standard units for several years [16]. However, since its beginning, the generation of excessive radiant energy was its main limitation, considering it to use only $1 \%$ of this energy to emit light [17]. These units possess bulbs with a lifetime between 50 to 100 hours $[11,18]$, and present a wavelength of 410 to 500 nanometers (nm), which

\footnotetext{
* Corresponding author: Fernando Mauricio Villalta Mendoza

Bachelor in General Dentistry Faculty of Dentistry, University of Cuenca.
} 
difficult the activation of materials with alternative photo activators with emission of light intensities oscillating between 400 to $800 \mathrm{~mW}^{*} \mathrm{~cm}-2[14,15,19]$. On the other hand, LED units started to be used in the '90s [20], this use joints with semiconductors to generate light, emitting wavelengths from 450 up to $486 \mathrm{~nm}[3,11]$ with intensities ranging between 1000 to $2000 \mathrm{~mW}^{*} \mathrm{~cm}-2$. These units present a lifetime of about 100 hours [13, 18] and can be presented as wire or wireless devices, they are noiseless due to no need for ventilation, with less weight, producing less heat [18], and allow less work time[21, 24]. Therefore, LED devices replaced halogen units and up to date are the most used and commercialized [16].

Both, halogen and LED devices, emit its light through optic fiber guides [20], available in the market in several diameters around 6 to $12 \mathrm{~mm}$, presenting the same size in its proximal and distal end [25-26]. It is recommended that the guide light does not present alterations such as grooves, fissures ,or fractures, as well as the presence of material residues in its structure, because of negative interferences with light intensity emitted [12, 27].

Dental radiometers are used to assess the light intensity emitted by the light-curing units, those are formed by silicon or selenium photodiodes that transform light into electric current and reflects it in a digital or analog meter [28]. ISO 10650 norm establishes the use of a laboratory power meter, calibrated according to the radiation emitted by the photopolymerization devices. However, this is distinctly for industrial use and dental radiometers have to be used for monitoring the lamps functioning in dental offices.

Shimokawa CAK et al., evaluated the accuracy of four dental radiometers ("Bluephase Meter II, SDI LED Radiómetro, Kerr LED Radiometer y LEDEX CM4000") and concluded that "Bluephase Meter II" (Ivoclar-Vivadent) radiometer does not shown significant differences compared to the power meter in laboratory. Therefore, this is a suitable device for light intensity measure 29], besides it is used for measuring intensities between 300 to $1200 \mathrm{~mW}{ }^{*} \mathrm{~cm}-2$ and wavelengths ranging from 380 to $550 \mathrm{~nm}$ [30].

The objective of the present study is to determine the light intensity, type, and status of the optic fiber in photocuration lamps used in several private offices of the city of Cuenca - Ecuador.

\section{Material and methods}

The present observational descriptive study selected 366 lamps through a no probabilistic sampling due to the scarce information of devices use in the city as well as limited resources for this study.

A Bluephase Meter II, Ivoclar-Vivadent was used to measure the light intensity of the devices. Guide light diameter was determined with the use of a stencil located in the back of the radiometer for its configuration before measurements.

Three measurements were done for each device considering a battery with maximum charge and continuous light output for LED type, allowing a variability of $25 \mathrm{~mW}^{*} \mathrm{~cm}-2$. Lamp type, brand, commercial model, presence or absence of fractures, and dental materials residues in the guidelight, as well as its diameter were recorded. All data were registered in a data form for this research.

Statistical analysis was done with the use of the software R v.3.2 and its interface R-Studio v.1.2. Chi-square and OneWay ANOVA tests with its respective Tukey post hoc analysis were developed to determine light intensity differences among devices and categories recorded. Also, a Pearson correlation coefficient was determined among all variables.

\section{Results}

67 out of 366 measurements registered negative values, which were considered as outliers and deleted from the database for the statistical analysis. Table 1 shows the proportion of Halogen and LED units with light intensities that meet or are below the required intensity. LED devices accounted for $82 \%$ of total units, registering $12 \%$ of its units with light intensities below $400 \mathrm{~mW}^{*} \mathrm{~cm}-2$. On the other hand, Halogen units represented $18 \%$ of the sample with intensities below required in $46 \%$ of its units. 
Table 1 Halogen and LED devices composition by intensity requirements in oral treatments.

\begin{tabular}{|l|l|l|l|}
\hline \multirow{2}{*}{} & \multicolumn{2}{|l|}{ Photocurate units } & Total (\%) \\
\cline { 2 - 4 } & Halogen (\%) & LED (\%) & \\
\hline Below required intensity & $24(46 \%)$ & $28(12 \%)$ & $52(18 \%)$ \\
\hline Meet Required intensity & $29(54 \%)$ & $218(88 \%)$ & $247(82 \%)$ \\
\hline Total & 53 & 246 & 299 \\
\hline
\end{tabular}

Halogen devices showed mean light intensities of 479,3 mW* $\mathrm{mm}-2$ with minimums of 303 and maximums of $1047 \mathrm{~mW}{ }^{*} \mathrm{~cm}-2$, while LED mean intensity was of $801 \mathrm{~mW}^{*} \mathrm{~cm}-2$ with min values of 310 and max of $2690 \mathrm{~mW}{ }^{*} \mathrm{~cm}-2.17 \%$ of total units presented fractures in its light guide, $52 \%$ presented dental materials residues, and $65 \%$ registered a diameter of $8 \mathrm{~mm}$.

Figure 1 shows the light intensity distribution for both Halogen and LED devices considering the presence or absence of fracture in the optic fiber. Absence of fractures resulted in significantly higher light intensities for both lamp types (p-value <0.03). As observed in Figure 2, light intensity was significantly higher in units with absence of biomaterials residues ( $\mathrm{p}$-value $<2.2 \mathrm{e}-05$ ). Also, significant differences of light intensity were determined according to optic fiber diameter. Such differences were attributed to the lower light intensities of diameter $9 \mathrm{~mm}$ in relation with $8 \mathrm{~mm}$ (Figure 3). The other diameter groups have not presented significant differences for light intensity.

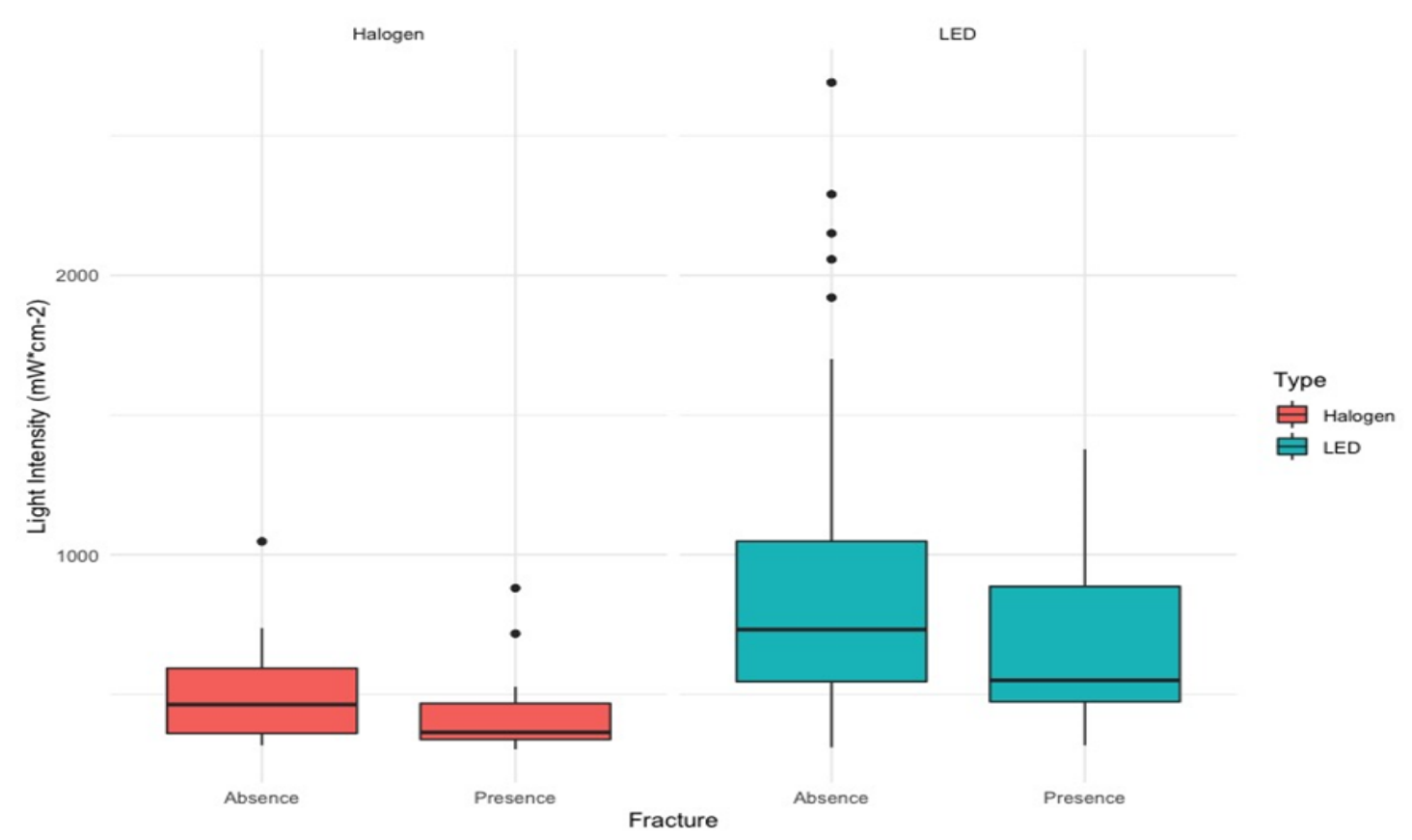

Figure 1 Light intensity distribution according presence/absence of fractures in device light guide. 


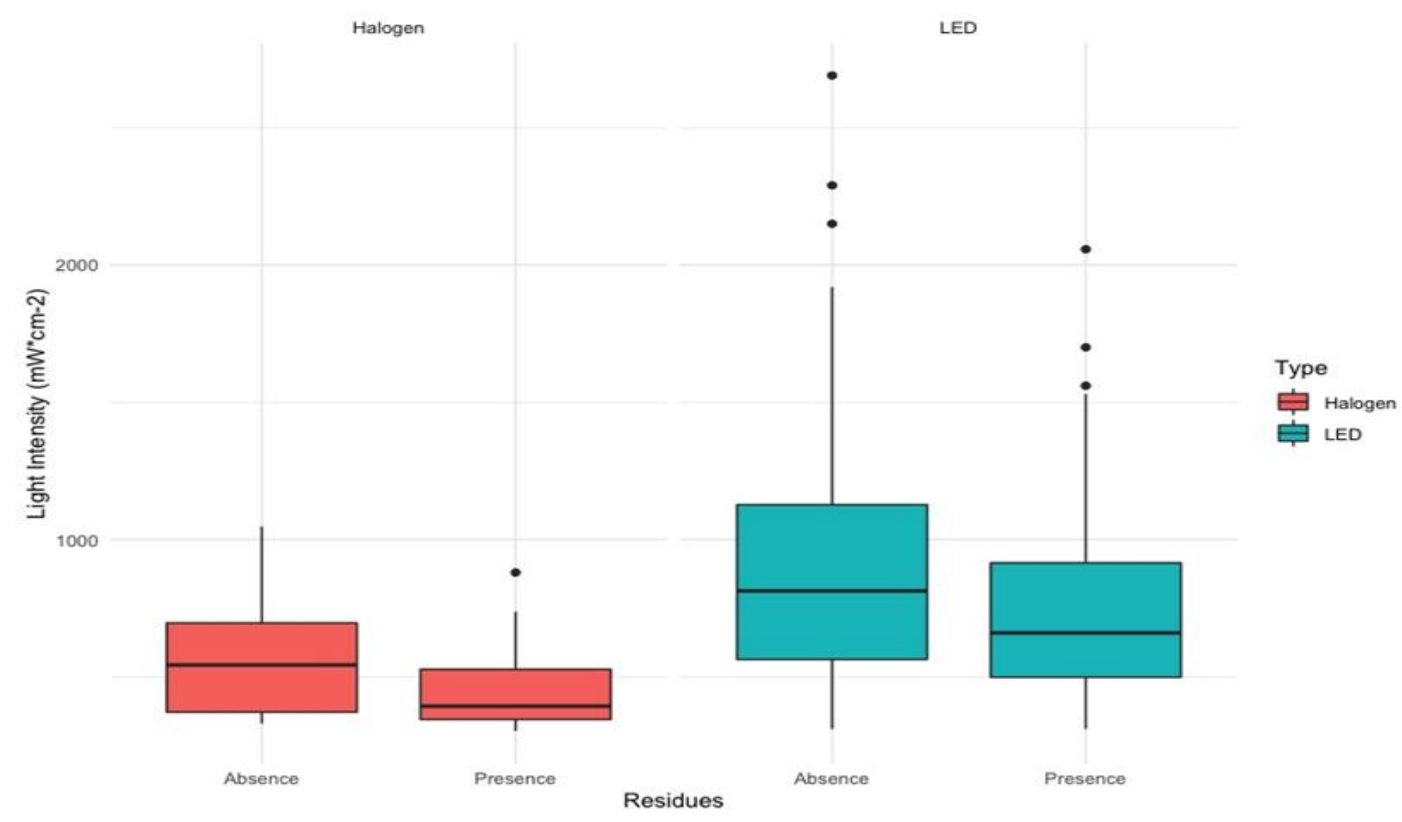

Figure 2 Light intensity distribution according presence/absence of residues in device light guide.

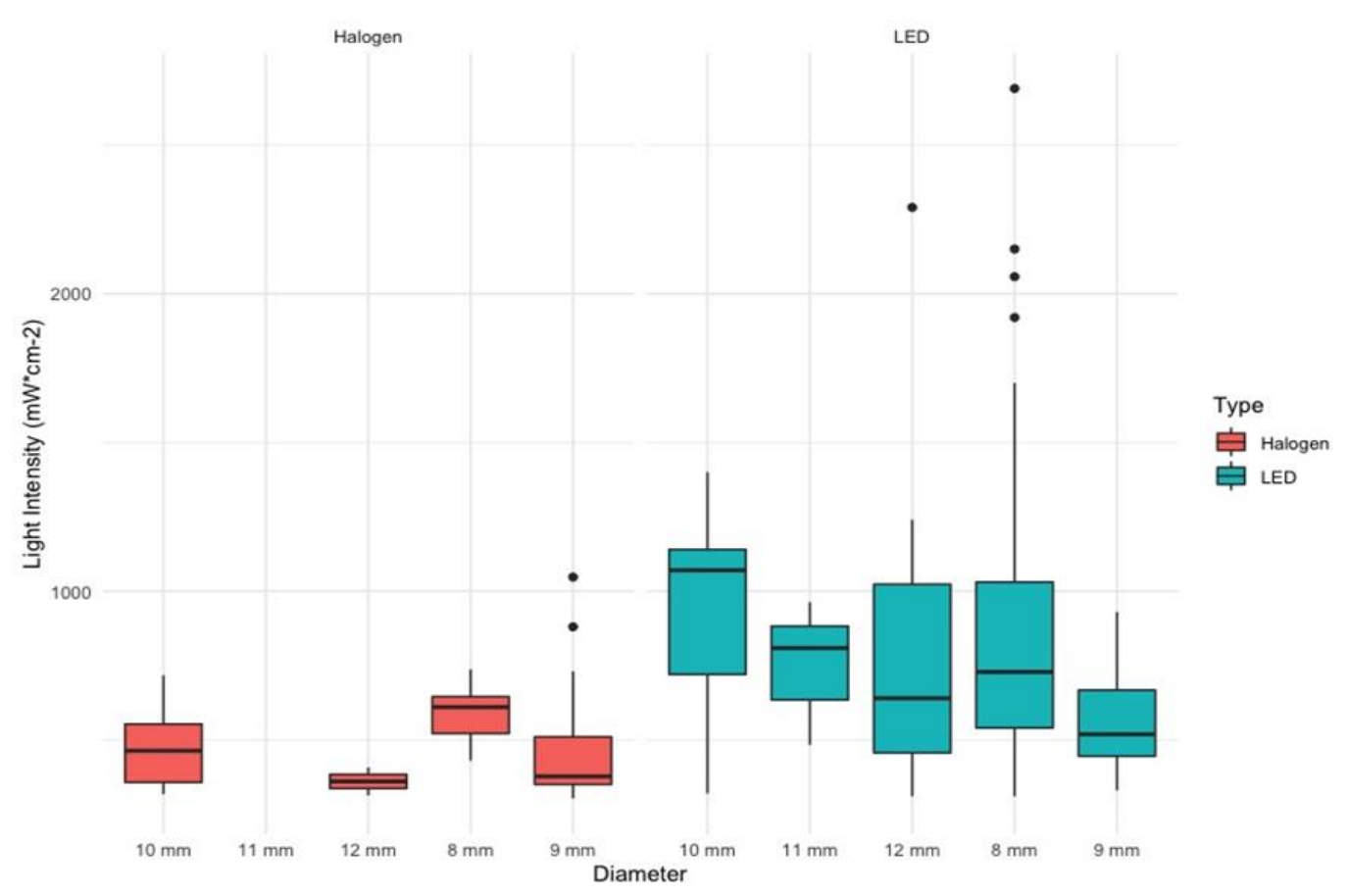

Figure 3 Light intensity distribution according to light guide diameter.

\section{Discussion}

Light intensity emitted by photocuration lamps is an important factor in the clinical practice and its monitoring must be continuous in order to avoid negative effects in dental treatments. The present study analyzed the light intensity emitted by devices used in private offices in the city of Cuenca, and compared its measurements with factors associated with the optic fiber of the devices, including the presence of materials residues, diameter, and type of lamp. 
Results indicate that $18 \%$ of analyzed units presented an inadequate light intensity $\left(<400 \mathrm{~mW} \mathrm{~cm}^{*} 2\right)$. Similar results were obtained by Eren D et al., where values below recommended intensity constituted 10, 7\% [7], as well as Alquria T et al., with 13\% [13]. However, Madhusudhana $\mathrm{K}$ et al., reported an increase of up to $44 \%$ of units with inadequate intensities [31].

Halogen units presented a higher percentage of inadequate intensities with $46 \%$ of its units in comparison to $12 \%$ of LED devices. These results contrast with those indicated by Omidi B-R et al., describing 97\% and 93\% of adequate intensities for Halogen and LED types respectively [12].

LED devices were most frequent (82\%) in comparison with Halogen (18\%), similar to results obtained by Alquria T et al., which showed a tendency of 88,5\% for LED over 11,5 of Halogen lamps [13]. Also, Nassar HM et al., indicated a higher frequency for LED $(82,9 \%)$ than Halogen $(17,1 \%)$ [9].

The mean light intensity of LED and Halogen devices in this study were 801 and 479, $3 \mathrm{~mW}^{*} \mathrm{~cm}-2$ respectively, similar to 865,2 and $527,6 \mathrm{~mW}^{*} \mathrm{~cm}-2$ registered by Alquria T et al., but higher to 598 and $260 \mathrm{~mW}{ }^{*} \mathrm{~cm}-2$ registered by Al Shaafi $\mathrm{M}$ et al. [8].

It has been determined that the presence of residues as well as fractures on the light guide had a negative influence on the light intensity emitted by the device. Similar results are presented by Madhusudhana K et al., which indicates that residues can block the light output [31]. Therefore, Sword R et al., recommends the use of polyvinyl or polyurethane translucid physical barriers, which does not interfere significantly with emitted intensity [32].

Results obtained in this study cannot be extrapolated by complete to the city of Cuenca due to the no probabilistic sampling, as well as values below $300 \mathrm{~mW}^{*} \mathrm{~cm}-2$ were not able to be recorded by the radiometer and exclusion of those records were done.

\section{Conclusion}

Most of particular dental offices use photocuration lamps with recommended light intensity, which is of importance to provide a guarantee in the several dental treatments for the patients. In the same way, LED devices are the most used, allowing dentists to done photopolymerization processes in less time compared with Halogen lamps use. Also, with the analysis of lamp characteristics, a low proportion (17\%) presented fractures in the optic fiber, and half sample (52\%) shown accumulation of biomaterials residues, which influence the device lifetime and performance. Thus, a correct cleaning and maintenance of the device is highly recommended.

\section{Compliance with ethical standards}

\section{Acknowledgments}

Acknowledgments to the dentists who allowed the preparation of the research. Thanks to all of you.

\section{Disclosure of conflict of interest}

All the authors state no conflict of interest for publishing this original manuscript.

\section{References}

[1] M Cadenaro, T Maravic, A Comba, A Mazzoni, L Fanfoni, T Hilton, et al. The role of polymerization in adhesive dentistry. Dental Materials. 2019; 35(1): e1-e22.

[2] R Price, J Ferracane, A Shortall. Light-curing units: a review of what we need to know. J. Dent. Res. 2015; 94(9): 1179-86.

[3] YR Lee, NRNA Ghani, MI Karobari, TY Noorani, MS Halim. Evaluation of light-curing units used in dental clinics at a University in Malaysia. J Int Oral Health. 2018; 10(4): 206.

[4] RB Price, FA Rueggeberg. Light Curing of Restorative Materials. Sturdevant's Art and Science of Operative Dentistry: Elsevier. 2019; 170-99. 
[5] A Yap, M Soh, K Siow. Effectiveness of composite cure with pulse activation and soft-start polymerization. Oper Dent. 2002; 27(1): 44-9.

[6] G Spagnuolo, M Annunziata, S Rengo. Cytotoxicity and oxidative stress caused by dental adhesive systems cured with halogen and LED lights. Clin Oral Investig. 2004; 8(2): 81-5.

[7] D Eren, F Tutkan. Investigation of the reliability of light-curing units in Sivas City, Turkey. Niger. J. Clin. Pract. 2019; 22(4): 469.

[8] MAl Shaafi, A Maawadh, MAl Qahtani. Evaluation of light intensity output of QTH and LED curing devices in various governmental health institutions. Oper Dent. 2011; 36(4): 356-61.

[9] HM Nassar, R Ajaj, F Hasanain. Efficiency of light curing units in a government dental school. J Appl Oral Sci. 2018; 60(1): 142-6.

[10] N Kramer, U Lohbauer, F Garcia-Godoy, R Frankenberger. Light curing of resin-based composites in the LED era. Am. J. Dent. 2008; 21(3): 135.

[11] GA Maghaireh, H Alzraikat, NA Taha NA. Assessing the irradiance delivered from light-curing units in private dental offices in Jordan. J Am Dent Assoc. 2013; 144(8): 922-7.

[12] BR Omidi, A Gosili, M Jaber-Ansari, A Mahdkhah. Intensity output and effectiveness of light curing units in dental offices. J. Clin. Exp. Dent. 2018; 10(6): e555.

[13] T Alquria, M Al Gady, A Khabeer, S Ali. Types of polymerisation units and their intensity output in private dental clinics of twin cities in eastern province, KSA: A pilot study. J. Taibah Univ. Medical Sci. 2019; 14(1): 47-51.

[14] MM AlShaafi. Evaluation of light-curing units in rural and urban areas. Saudi Dent J. 2012; 24(3-4): 163-7.

[15] AMC Gil, YM Ojeda, JÁ Rodríguez. Evolución histórica de las lámparas de fotopolimerización. Rev. habanera cienc. médi. 2016; 15(1): 8-16.

[16] CRG Torres. Modern Operative Dentistry: Principles for Clinical Practice: Springer Nature. 2019.

[17] N Barghi, T Berry, C Hatton. Evaluating intensity output of curing lights in private dental offices. J Am Dent Assoc. 1994; 125(7): 992.

[18] A Goyal, H Jyothikiran. Use of Light Curing Units in Orthodontics: A Review. Research \& Reviews: A J Dent. 2019; 2(1-3): 69-75.

[19] P Segal, D Lugassy, E Mijiritsky, M Dekel, A Ben-Amar, Z. Ormianer, et al. The effect of the light intensity and light distances of led and qth curing devices on the hardness of two light-cured nano-resin composites. Adv Mater Sci Appl. 2015; 6(11): 1071.

[20] A Reis, A Loguercio. Materiales dentales directos de los fundamentos a la aplicación clínica. Sao Paulo: Santos. 2012.

[21] SE Bishara, R Ajlouni, C Oonsombat. Evaluation of a new curing light on the shear bond strength of orthodontic brackets. Angle Orthod. 2003; 73(4): 431-5.

[22] NS Koupis, T Eliades, AE Athanasiou. Clinical evaluation of bracket bonding using two different polymerization sources. Angle Orthod. 2008; 78(5): 922-5.

[23] R Mills, K Jandt, S Ashworth. Dental composite depth of cure with halogen and blue light emitting diode technology. Br Dent J. 1999; 186(8): 388-91.

[24] D Mirabella, R Spena, G Scognamiglio, L Luca, A Gracco, G Siciliani. LED vs halogen light-curing of adhesiveprecoated brackets. Angle Orthod. 2008; 78(5): 935-40.

[25] CP Ernst, RB Price, A Callaway, A Masek, H Schwarm, I Rullmann et al. Visible light curing devices: irradiance and use in 302 German dental offices. J Adhes Dent. 2018; 20(1): 41-55.

[26] A Shortall, R Price, L MacKenzie, F Burke. Guidelines for the selection, use, and maintenance of LED light-curing units-Part 1. Br Dent J. 2016; 221(8): 453-60.

[27] RB Price, AC Shortall, WM Palin. Contemporary issues in light curing. Oper Dent. 2014; 39(1): 4-14.

[28] D Marović, S Matić, K Kelić, E Klarić, M Rakić, Z Tarle. Time dependent accuracy of dental radiometers. Acta Clin Croat. 2013; 52(2): 173-80. 
[29] RB Price, FA Rueggeberg. Light Curing of Restorative Materials. Sturdevant's Art and Science of Operative Dentistry: Elsevier. 2019; 170-99.

[30] CAK Shimokawa, JE Harlow, ML Turbino, RB Price. Ability of four dental radiometers to measure the light output from nine curing lights. J Dent. 2016; 54: 48-55.

[31] I Bluephase Meter. Instructions for Use. Schaan Liechtenstein: Ivoclar Vivadent. 2015.

[32] K Madhusudhana, TV Swathi, C Suneelkumar, A Lavanya. A clinical survey of the output intensity of light curing units in dental offices across Nellore urban area. SRM SRM J Res Dent Sci. 2016; 7(2): 64.

[33] RJ Sword, UN Do, JH Chang, FA Rueggeberg. Effect of curing light barriers and light types on radiant exposure and composite conversion. J Esthet Restor Dent. 2016; 28(1): 29-42.

\section{Author's short biography}

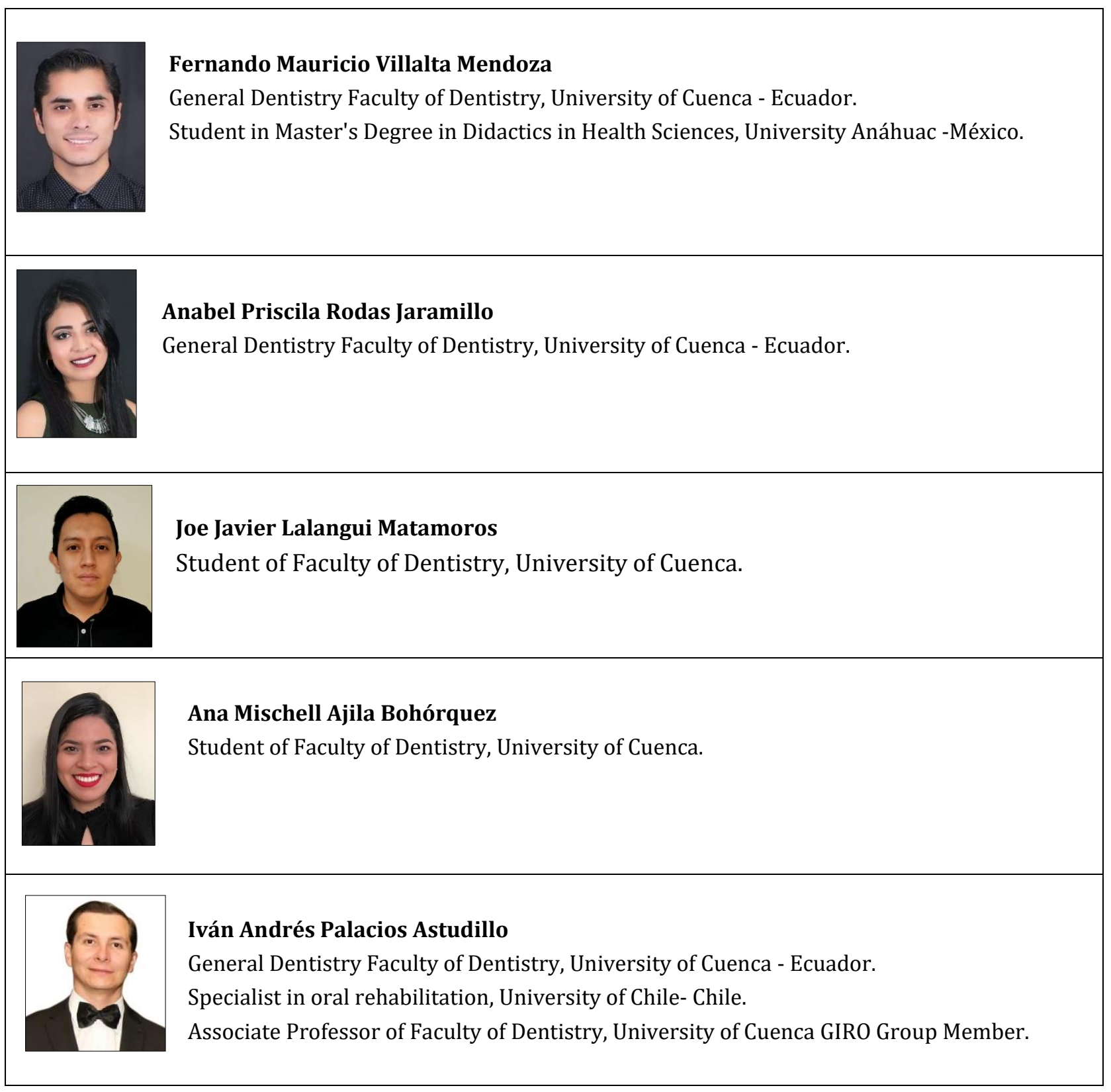

